\title{
The Impact of Using Dynamic Assessment on Iranian's Writing Literacy
}

\author{
Firooz Sadighi \\ Department of English Language, Islamic Azad University, Shiraz Branch, Shiraz, Iran \\ Fatemeh Jamasbi \\ Department of English Language, Islamic Azad University, Shiraz Branch, Shiraz, Iran \\ Sara Ramezani \\ Department of English Language, Islamic Azad University, Shiraz Branch, Shiraz, Iran
}

\begin{abstract}
Although using Dynamic Assessment especially in educational setting has been revealed to be a useful approach in helping learners to achieve higher levels of learning, not much consideration has been given to the role of teacher mediation through Dynamic Assessment in teaching writing literacy (Persian language). This study aimed to explore possible effects of teacher mediation on Iranian students' Persian writing skills. To this end 30 Iranian Persian students were selected as participants of the study. The treatment group was taught writing skill through DA by using Flexible mediation, but the control group without receiving any mediation. A non-dynamic pre- and post-test writings were given to both groups to determine any differences in their writing performance. At the end of the treatment a semi-structured interview was used to know the experimental group's opinion about their teacher's assistance. The data was subjected to the statistical procedure of $t$-test and the results indicated that not only all the students of experimental group outperformed the students of control group but according the semi-structured interview, DA acted as low affective filter for them since they saw teacher as an assistant during their writing and their improvement increased their motivation.
\end{abstract}

Index Terms—dynamic assistance, writing literacy, Persian language, L1

\section{INTRODUCTION}

Apart from traditional ways of assessment, dynamic assessment (DA) which lies in the work of Vygotsky (1978) and his colleagues (Feuerstein, Falik, \& Feuerstein, 2003; Feuerstein, Rand, \& Hoffman, 1979) is built upon the notion that instruction and assessment occur in a simultaneous way. In DA a mediator (teacher or peers) provides assistance for the learner while simultaneously examining the learner's abilities (Lantolf \& Pohner, 2004; Lidz \& Gindis, 2003). Lantolf (2000) points out that based on SCT framework each individual does not interact directly with the environment and uses culturally designed artifacts which are designed and created by human beings over time. Considering the differences between dynamic assessment (DA) and what is called static assessment (SA) is of great importance. Pohner and Lantolf(2003) believed that the concept of future makes distinction between dynamic assessment and static assessment. Based on DA future performance of the learner (potential level) is quite different from his/her current level of development. This is in line with learning issues where DA mainly focuses on the processes of learning and development while SA emphasizes the final product of learning mainly in the form of summative assessment.

\section{LITERATURE REVIEW}

\section{Sociocultural Theory (SCT), Zone of Proximal Development (ZPD), and Mediation}

Sociocultural Theory (SCT) built upon the work of Russian psychologist, Vygotsky and his colleagues, emphasizes the developmental aspect of human beings. SCT emphasizes the mediated process of individual functioning organized by culturally designed artifacts, behaviors, and notions (Ratner, 2002).

A pivot part of Vygotsky's SCT is the concept of the Zone of Proximal Development (ZPD).Based on Vygotsky's (1978) definition, ZPD is the distance between the current level of individual's development as attained through problem solving independently and the actual level of development through interaction with more knowledgeable ones. Regarding the concepts of sociocultural theory and ZPD, it is supposed that the developmental aspect of human beings is mediated by others. This kind of mediation provides constant feedback during the process of learning.

Lantolf and Thorne (2006) note that, the SCT defines mediation as 'the process through which humans deploy culturally constructed artifacts, concepts and activities to regulate the material world or their own and each other's social and mental activity' (p.79). The following quotation from Lantolf (2000) explains in details the importance of mediation in the process of human's mental development: 
The central and distinguishing concept of sociocultural theory is that higher forms of human mental activity are mediated. Vygotsky argued that just as humans do not act directly on the physical world but rely, instead, on tools and labor activity, we also use symbolic tools, or signs, to mediate and regulate our relationships with others and with ourselves. Physical and symbolic tools are artifacts created by human cultures over time and are made available to succeeding generations, which often modify these artifacts before passing them on to future generations (p. 80).

\section{Dynamic Assessment (DA) and Static Assessment}

Historically, two forms of assessment were defined for educational purposes: formative and summative. According to Bachman (1990) summative assessments are hold at the end of instructional period to see the final product of learning process whereas formative assessments are hold before completion of a course. Both of these assessment techniques especially summative emphasize the final product of learning.

Some critics like Pohner and Lantolf (2005) and Torrance and Pryor (1998) note that such traditional forms of assessment lack what is called the relationship between assessment and learning. They believe that these forms regard instruction and assessment as separate entities. As a result, Sternberg and Grigerenko (2002) decided to have a fundamental change in the forms of assessments to integrate instruction and assessment into a unified entity. Mediated assistance is another feature that distinguishes DA from SA.

According to Lantolf and Pohner (2004) this kind of mediation has two forms: sandwich and cake. The sandwich form includes three stages: pre-test, mediation, and post-test. Sternberg and Grigerenko (2002) mention that the issues used for pre-tests and post-tests tasks should be in the ZPD, and creating optimal ZPD should be the goal of mediator (teacher or peers). The cake format comprises feedback on the part of the examiner during the test administration. If the learner can not accomplish the task given by the examiner, she/ he will be mediated in the form of pre-fabricated hints and prompts (Sternberg \& Grigorenko, 2002, p.27).

\section{Teacher Assisted mediation}

As it was mentioned one of the main features that make Dynamic Assessment quite different from traditional assessment is the concept of mediation. Mediation is defined as the optimal assistance by the teacher or peer to the learners before or during the assessment process in order to help them develop their potential abilities and move toward their ZPD. This mediated assistance is located at the heart of Dynami Assessment (DA) concept. Vygotsky (1986) believes that language is the most significant tool for mediation and mediates individual developmental process through what is called the process of internalization (Vygotsky, 1994). Aljaafreh and Lantolf (1994) present three ideal conditions for mediation. First, mediation should be graduated so that the mediator (teacher or peer) can provide help in the form of different prompts, hints, questions, gestures, or clear explanations. These forms of mediation should start from the most implicit to the most explicit ones. Second, mediation should be contingent and should be offered whenever it is needed. Third, mediation should be dialogic in the form of dialogue between the teacher or peer and the learner. Based on Lantolf and Pohner's(2004) classification, there are also two forms of dynamic assessment called interventionist and interactionist. Lantolf and Poehner (2004) note some differences between these two forms; the interventionist emphasizes the efficiency of learning and speed but the interactionist related to the ZPD, focuses on interaction between a learner and a mediator. All elements in interventionist DA are pre- scripted while in interactionist DA the role of mediator in the process of learning becomes crucial.

\section{Empirical Studies on Dynamic Assessment}

Inspection of the literature on Dynamic Assessment (DA) and mediation shows the effectiveness of mediation in learning different skills and sub- kills of English.

Antón (2003) reported the usefulness of DA in testing language proficiency of advanced L2 learners. The learners were provided with different prompts (mediation) through dialogic teacher-learner interactions. The results of the study also indicated that the inclusion of mediation resulted in an increase in the test's ability of learner's writing and speaking skills.

Lantolf and Poehner's (2011) study showed the positive effect of DA in the fourth and fifth grade Spanish classrooms. In this study, the mediator (teacher) used organized mediation prompts to assess noun/adjective agreement in Spanish.

Sadeghi and Khanahmadi (2011) investigated the role of DA based versus non-DA based activities in learning L2 grammar of Iranian EFL learners. The results mainly showed that the type of instruction based on DA (mediation) made a meaningful difference in the learning of grammar by Iranian EFL learners.

The use of teacher mediation within a DA framework to assist business students in open and distance educational contexts conducted by Shrestha, Prithvi and Coffin (2012). The study revealed the role and positive effect of teacher mediation in the context of academic writing development among undergraduate business students studied in open and distance learning, following the DA.

To summarize, a brief overview of the a few studies done in the area of Dynamic Assessment (DA) especially in educational context reveals the usefulness of this approach in helping learners to achieve higher levels of learning. Although there are series of studies whose concern is mainly about the effect of teacher mediation on the writing performance of L2 learners, (e.g., Shrestha, et.al, 2012; Alemi, 2015; Hashemnezhad \& Fatollahzadeh, 2015; Sadek, 2015; Mauludin\& Ardianti 2017), little research exists examining the role of teacher mediation through dynamic assessment in teaching Persian (L1)writing. This study aims to explore possible effects of teacher mediation on Iranian students' writing skill. 
To achieve this goal the following research question is posed:

1. What is the effect of using Dynamic Assessment in L1 writing?

2. What are the students' attitudes towards DA for their writing skill?

\section{MethodolOGY}

\section{Participants}

This study was conducted with 30 weak Iranian Persian students in writing skill (males) who were selected from an available population of 75 students from three high schools in Shiraz, Iran. The participants were 16 years old. The native language of all the students were Persian.

For the teacher participants of the study, three male teachers who were 38, 42 and 32 years old with an average experience of 10 and 11 and 5 years respectively accepted to participate in the study.

\section{Materials}

The researchers used the high school writing 1 book by Education department of Iran, Tehran which was used as the course material for grade 10 students in Iran. The book consisted of 4 sections from which unit 2 was worked on for the students during 5 sessions on the basis of the book information. This part relates to 'exemplification', that is a technique to recreate and extend the original text. This technique of writing is effective in conveying your thought, writing more beautifully, improving the speech and writing power.

\section{Instruments}

Two writing tests (a pre and a posttest) were taken in which the students were asked to write about a particular topic on the basis of the topics provided in that section of their writing book for about one hour on the basis of Persian writing book scale for grade (see Appendix A)

\section{Procedures}

In this study, three Persian native teachers of the high school were trained how to use dynamic assessment in their teaching writing skill to students in 3 sessions. In the first session, the researchers introduced the notion of dynamic assessment to them. In the second section, they provide the instructors with more explanation of the DA and provide some theoretical examples to them. In the third session, the researchers did DA on two students' writing skill to make the issue tangible for the teachers.

Before the teachers start their treatment sessions, a non-dynamic pre-test was given to the Persian native students to see how their writing ability is. Among all the students, only the students who had the lowest grades were selected as the researchers aimed to find a way to help the native students in situations they face problems at school. The topic of their pretest was chosen from the issues in their writing book. Then, they were divided into 2 groups (experimental and control groups). As DA needs careful attention and it is more practical for small number of participants the experimental and control groups were divided into 6 classes of 5 students (3 classes with DA and the other 3 with typical way of teaching). Then, the treatment started as they were taught writing skill with DA through 5 sessions in which the teachers were turning around the students and looking at each student writing separately and used flexible mediation depending on the needs of the students for their writing to help them do their best. Flexible mediation was conducted in the form of a dialogue between the teacher and the learner. As an example, one of the students didn't know what to write about the topic of "easy come, easy go"

Teacher: Why do you think about the histories in your history book?

Student: Because I don't think there is any relation between the writing and history.

Teacher: But look at the topic. What is it about? Read it carefully.

Student: It is about "easy come, easy go".

Teacher: Does it remind you any story?

Student :.... (Thinking)

Teacher: Think a little more

Student: Yeah, teacher. Khosrow Parviz, one of the Sassanid king.

Teacher: Very good. Now you can get the ideas from his life.

Finally, the students took a non-dynamic post-test to see how effective was DA on their L1 writing.

Data Analysis Procedures

The pre and post-tests codified on the basis of the scale for measuring of the students' writing at the end of each unit of the book by two raters were submitted to SPSS program for analysis. The scales were designed by education department of Iran, Tehran to provide a unified scoring scale on the basis of each part's writing aim. This is helpful to avoid the subjectivity of scoring as much as possible. Pearson Correlation analysis was carried out both in pre and posttests between the two raters' scores which can be evidence for the reliability of their given scores.

TABLE 1.

PEARSON CORRELATION BETWEEN TWO RATERS' GIVEN SCORES IN THE PRE AND POST-TEST

\begin{tabular}{|l|l|l|}
\hline & Pre-test & Post-test \\
\hline Pearson correlation & .848 & .895 \\
\hline Sig & .000 & .000 \\
\hline N & $\mathbf{3 0}$ & $\mathbf{3 0}$ \\
\hline
\end{tabular}


With regard to the above Table, the first and second raters' given scores to the participants' writing appeared to have very high correlation $(r=.000, \mathrm{P}>.01)$ in their pre and posttest's ratings indicating a high agreement of their judgment.

\section{RESULTS}

\section{Descriptive statistics}

As for the analysis of the data, the descriptive statistics of the pre and post-test writing scores of each group (Control and Experimental groups) are presented in the following table.

TABLE 2.

DESCRIPTIVE STATISTICS OF THE SCORES

\begin{tabular}{|l|l|l|l|}
\hline Groups & Pre-test & Post-test \\
\hline \multirow{2}{*}{ Control group } & N of participants & $\mathbf{3 0}$ & $\mathbf{3 0}$ \\
\cline { 2 - 4 } & Mean & $\mathbf{1 2 . 1 3}$ & $\mathbf{1 3 . 0 6}$ \\
\hline \multirow{2}{*}{ Experimental group } & N of participants & $\mathbf{3 0}$ & $\mathbf{3 0}$ \\
\cline { 2 - 4 } & Mean & $\mathbf{1 1 . 5 3}$ & $\mathbf{1 7 . 8 0}$ \\
\hline
\end{tabular}

As indicated in Table 2, Although both groups did better in the posttest but the control group had little improvement. Thus, the improvement of the learners can be attributed to the DA treatment.

\section{Research questions}

1. What is the impact of DA on Persian Iranian L1 writing skill?

TABLE 3.

DESCRIPTIVE STATISTICS FOR THE EXPERIMENTAL GROUP

\begin{tabular}{|c|c|c|c|}
\hline \multicolumn{2}{|l|}{ Descriptives } & Pre-test & Post-test \\
\hline \multirow[t]{3}{*}{ Experimental group } & $\mathrm{N}$ of participants & 30 & 30 \\
\hline & Mean & 11.53 & 17.80 \\
\hline & SD & 1.64 & .86 \\
\hline \multirow[t]{3}{*}{ Control group } & $\mathrm{N}$ of participants & 30 & 30 \\
\hline & Mean & 12.13 & 13.06 \\
\hline & SD & 1.76 & 1.53 \\
\hline
\end{tabular}

According to Table 4, the mean scores for the pre-tests of control and experimental groups are 12.13 and 11.53 respectively which shows they are almost the same but the mean score for the post-test scores of them are 13.06 and 17.80, Respectively. The standard deviation for the former is 1.53 and that of latter is .86. On the basis of Table 2 , although the learners' writing skill was developed in both groups, the mean score and the standard deviation indicate that the participants in the experimental group acted better than the control group.

TABLE 4.

T-TEST FOR THE DIFFERENCE BETWEEN THE MEAN SCORES OF CONTROL AND EXPERIMENTAL GROUPS' POST-TESTS

\begin{tabular}{|l|l|l|}
\hline Mean difference & T & Sig \\
\hline-4.73 & -10.420 & .000 \\
\hline
\end{tabular}

Table 4 represents the results of the t-test run for the difference between the means of the control group and experimental group. On the basis of Table 3, the difference between the two groups is statistically significant $(\mathrm{t}=-10.420$, $\mathrm{P}<0.05)$. Thus, as mentioned above, the mean score of the experimental group is higher than the other group. One claim that applying DA helps the learners to develop their writing skill much more than the usual method of teaching.

2. What are the students' attitudes towards DA for their writing skill?

After interviewing the students, almost all agreed that their teacher' assistance helped them to write more accurately. The teacher's hints helped them to think better and remember many things they had forgotten. Teacher's assistance helped them to get better grades and motivated them to write better. They focused more on punctuation marks.

With the assistance of their teacher, they could write what they aimed to. So it led to their willingness to write. For instance one of the students said that he used to feel nervous about writing and couldn't write well but with the help of his teacher he had been able to write a coherent paragraph and motivated more to write better. Another student believed he felt closer to the teacher and it reduced his stress and led him to write easily with more confidence.

\section{DISCUSSION}

The purpose of the study was to show the effective of DA on Persian L1 writing skill. The independent samples t-test analysis of the pretest revealed that there was no significant difference $(p<.05)$ between the mean scores of the participants in the two groups which is an indicator of their homogeneity in terms of their writing performance at the beginning of the training. The researchers began to apply graduated prompting procedure of DA to the experimental group, but not to the control group. To see the improvement of the students' writing skill in both experimental and control groups' writing performance and compare them, they took a posttest at the end of the training.

As shown in the results, the mean scores of the experimental group were significantly different from those of the control group. In fact, students' L1 writing performance surpassed the control group (Table 3). 
This finding adds to the reviewed studies revealing that graduated prompting procedure of DA was effective not only on facilitating L2 writing but also it is useful for writing improvement on L1. In fact, it confirms the effect of DA on both SL/FL proficiency skills and L1 literacy skills. In a study by Taheri and Dastjerdi (2016), the effect of DA intervention in identifying and supporting Iranian EFL learners' writing ability was shown in which DA approach could successfully improve EFL learners' writing ability. Moreover, there are a number of researchers whose findings were in line with this study in the case that DA is effective on students' writing skills (e.g. Shrestha, et.al, 2012; Alemi, 2015; Hashemnezhad \& Fatollahzadeh, 2015; Sadek, 2015; Mauludin\& Ardianti 2017).

Finally, in order to see the Persian Iranian high school learners' attitudes towards the use of graduated prompting procedure of DA for their writing skill, the researchers interviewed them. The students' attitude in the experimental group towards the method used was positive and result in increasing their motivation and scores.

\section{CONCLUSION}

This study aimed at investigating the effect of DA on Persian Iranian learners' L1 writing skill at high school. As it appeared in the discussion part, this method helped learners improve their L1 writing which became a trouble issue for them. In other words, the students of the experimental group outperformed the control group after the treatment. In addition, based on learners' interviews, DA acted as low affective filter for them since they saw teacher as an assistant during their writing and their improvement increased their motivation which is an essential issue for doing any job in people's life.

\section{LIMITATIONS OF THE STUDY}

Like all other studies, the current research is not simply without limitations. This study didn't take gender into account since the researcher had access to male students only.

\section{SUGGESTIONS FOR FURTHER RESEARCH}

In line with the above limitation, future research is required to examine the effect of DA on L1 writing skill for both males and females. Another research is also vital to investigate the effect of DA on the other L1 literacy language skill (reading).

\section{APPENDIX. MARKING OF THE WRITTEN EXAM}

\begin{tabular}{|l|l|l|l|}
\hline Evaluation Criteria & value & Descriptive Report & Numerical Report \\
\hline $\begin{array}{l}\text { Producing coherent text: } \\
\text { - Concrete using senses } \\
\text { - Abstract using mental creativity }\end{array}$ & 5 & & \\
\hline Avoiding redundancy & 5 & & \\
\hline Sentence structures and accuracy & 5 & & \\
\hline Readability & 2 & & \\
\hline $\begin{array}{l}\text { Accurate spelling and } \\
\text { punctuation notes }\end{array}$ & 3 & & \\
\hline Total & 20 & & \\
\hline
\end{tabular}

\section{REFERENCES}

[1] Alemi, M. (2015). The Impact of Dynamic Assessment on Iranian EFL students' Writing Self-Assessment. TELL, 9(1), 145169.

[2] Aljaafreh, A., \& Lantolf, J. P. (1994). Negative feedback as regulation and second language Learning in the zone of proximal development. The Modern Language Journal, 78(4), 465-483.

[3] Antón, M. (2003). Dynamic assessment of advanced foreign language learners. Paper presented at the American Association of Applied Linguistics, Washington, D.C., March.

[4] Bachman, L., F. (1990). Fundamental considerations in language testing. New York: Oxford University Press.

[5] Bachman, L.F. (1990). Fundamental consideration in language testing. Oxford: Oxford University Press.

[6] Feuerstein, R., Falik, L., Rand, Y., \& Feuerstein, R. S. (2003). Dynamic assessment of cognitive modifiability. Jerusalem: ICELP Press.

[7] Feuerstein, R., Rand, Y., \& Hoffman, M. B. (1979). The dynamic assessment of retarded performers: The learning potential assessment device, theory, instruments, and techniques. Baltimore, MD: University Park Press.

[8] Hashemnezhad, H., \& Fatollahzadeh, F. (2015). The immediate and delayed effect of dynamic assessment on the improvement of iranian EFL learners' writing performance. International Journal of Language Learning and Applied Linguistics World, 8(2), 193-209.

[9] Lantolf. (2000). Sociocultural theory and second language learning. Oxford: Oxford University Press.

[10] Lantolf, J. P., \& Poehner, M. E. (2004). Dynamic assessment of L2 development: bringing the past into the future. Journal of Applied Linguistics, 1(1), 49-72. 
[11] Lantolf, J.P., \& Poehner, M. (2011). Dynamic assessment in the classroom: Vygotskian praxis for L2 development. Language Teaching Research, 15(11), 11-33.

[12] Lantolf \& Thorne. (2006). Sociocultural theory and the genesis of second language development. Oxford: Oxford University Press.

[13] Lidz, C. S., \& Gindis, B. (2003). Dynamic assessment of the evolving cognitive functions in children with typical and atypical development. In A. Kozulin, V. Ageyev, S. Miller, \& B. Gindis (Eds.), Vygotsky's theory of education in cultural context (pp. 99-116). New York, NY: Cambridge University Press.

[14] Mauludin, L. A. \& Ardianti, T. M. (2017). The Role of Dynamic Assessment in EFL Writing Class. METATHESIS, 1(2), 82-93.

[15] Poehner, M. E., \& Lantolf, J. P. (2003). Dynamic assessment of L2 development: Bringing the past into future. CALPER Working Papers Series, No. 1. University Park, PA: The Pennsylvania State University, Center for Advanced Language Proficiency Education and Research.

[16] Poehner, M. E., \& Lantolf, J. P. (2005). Dynamic assessment in the language classroom. Language Teaching Research, 9(3), 233-265. doi:10.1191/1362168805lr166oa.

[17] Ratner, C. (2002). Cultural psychology: Theory and method. New York: Kluwer/Plenum.

[18] Sadeghi, K., \&Khanahmadi, F. (2011). Dynamic assessment of L2 grammar of Iranian EFL learners: The role of mediated learning experience. International Journal of Academic Research, 3(2), 931-935.

[19] Sadek, N. (2015). Dynamic Assessment (DA): Promoting Writing Proficiency through Assessment. International Journal of Bilingual \& Multilingual Teachers of English, 2(2), 59-70.

[20] Shrestha, P., \& Coffin, C. (2012). Assessing Writing Dynamic assessment, tutor mediation and academic writing development. Assessing Writing, 17(1), 55-70.

[21] Sternberg, R. J., \& Grigorenko, E. L. (2002). Dynamic testing. New York, United States of America: Cambridge University Press.

[22] Taheri, R. \& Dastjerdi, H. V. (2016). Impact of Dynamic Assessment on Iranian EFL Learners' Picture-cued Writing. International Journal of Foreign Language Teaching and research 4(13), 129-144.

[23] Torrance, H. \& Pryor, J. (1998). Investigating Formative Assessment: teaching, learning and assessment in the classroom. Buckingham: Open University Press.

[24] Vygotsky, L. S. (1986). Thought and Language. Cambridge, MA: MIT Press.

[25] Vygotsky, L. S. (1978). Mind in society: The development of higher psychological process. Cambridge: Harvard University Press.

[26] Vygotsky, L. S. (1994). The problem of the cultural development of the child. In R. Van der Vee \& J. Valsiner (Eds.). The Vygotsky reader. Cambridge, MA: Blackwell.

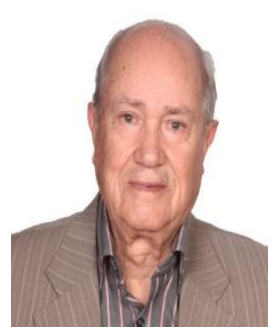

Firooz Sadighi (b.1939. Bavanat, Iran) is a professor of English Language and Linguistics at Shiraz University and Islamic Azad University. He received his Ph.D. from the University of Illinois, USA in 1982. He has taught courses such as 'psycholinguistics', 'First Language Acquisition', 'Second Language acquisition' and 'Syntactic Argumentation' in the Ph.D. program in TEFL. He has published numerous articles (locally and internationally) and books. He has also supervised several M.A theses and Ph.D. dissertations at the Department of Foreign Languages and Linguistics and Azad University. His research areas are 'foreign/second language learning and teaching', 'linguistics including syntax, semantics, and phonology' and 'syntactic argumentation'.

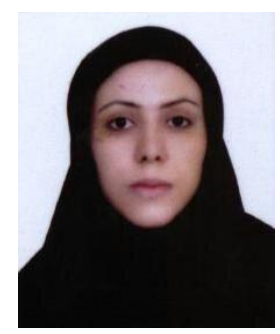

Fatemeh Jamasbi (b.1986, Shiraz, Iran) is a Ph.D. candidate of TEFL at Shiraz Islamic Azad University. She received her BA and MA from the same university. She has taught EFL for ten years at different language institutes in Shiraz. Her research interests include psycholinguistics, CALL, and foreign language learning and teaching.

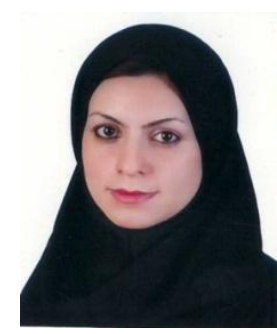

Seyyide Sara Ramezani (b. 1988, Shiraz, Iran) is a Ph.D. candidate of TEFL at Shiraz Islamic Azad University. She received her BA in English Literature and MA in TEFL from Shiraz University, Iran. 